\title{
QUESTÕES, OBJETOS E PERSPETIVAS EM AVALIAÇÃO
}

\author{
Almerindo Janela Afonso* \\ Recebido: 5 mar. 2014 \\ Aprovado: 30 maio 2014 \\ *Instituto de Educação Universidade do Minho, Braga, Portugal. E-mail:ajafonso@ie.uminho.pt
}

Resumo:O texto pretende revisitar e sinalizar alguns problemas que se colocam ao campo da avaliação educacional. Tendo em conta o ensino não superior, o autor faz a crítica à excessiva centralidade da avaliação dos alunos, à qual tem vindo a subordinar-se (frequentemente de forma contraditória e com consequências muito discutíveis) a avaliação institucional das escolas, a avaliação do desempenho profissional dos professores e, mesmo, a avaliação das políticas educacionais. Chamando a atenção para a necessidade de constituir como objeto de estudo as conexões e interações entre as diferentes formas de avaliação, o artigo também coloca em causa as chamadas políticas de responsabilização, e sublinha, em consequência disso, ser urgente pensar em formas alternativas de accountability.

Palavras-chave: Avaliações. Políticas de avaliação. Accountability.

\section{QUESTIONS, OBJECTS, AND PERSPECTIVES IN EVALUATION}

Abstract: The paper aims to revisit or signal some issues facing the field of educational evaluation. Among other issues, the author criticizes the excessive centrality of non-higher education student assessment. This fact has a questionable impact on the evaluation policies, on the institutional evaluation of schools and on the appraisal of the professional performance of teachers. Drawing attention to the need to study the connections and interactions between the different forms of evaluation, this paper also questions the so-called blame policies, arguing that it is crucial to consider alternative forms (and practices) of accountability.

Key words: Evaluations. Evaluation policies. Accountability. 
Começo por observar desde já que as reflexões que em seguida desenvolverei dizem respeito essencialmente ao ensino não superior. É neste âmbito que passarei a convocar, de uma forma sucinta, mas mais sistematizada, o que foram alguns dos tópicos sobre avaliação educacional que apresentei anteriormente de forma menos formal e mais dialógica, ainda que mantendo aqui uma intencionalidade tendencialmente ensaística ${ }^{1}$.

Numa época em que, por razões diversas, a avaliação das aprendizagens, a avaliação institucional das escolas, a avaliação do desempenho docente e a própria avaliação de políticas coexistem nos sistemas educativos, torna-se indispensável, do meu ponto de vista, chamar a atenção para a necessidade de analisar criticamente a excessiva centralidade da avaliação dos alunos, à qual todas as outras avaliações parecem subordinar-se ou referenciar-se.

Observo ainda, de passagem, que o debate a favor de uma ciência da avaliação (ou uma transdisciplina da avaliação) versus a assunção da avaliação como um campo (no sentido sociológico), apesar de ser alimentado por perspetivas e argumentos diferenciados, converge na preocupação de reforçar a dignidade da avaliação e da correspondente complexidade das suas teorias e metodologias - em clara oposição com a profundamente redutora e conservadora avaliocracia neopositivista, hoje dominante.

Chamo ainda a atenção para a necessidade de constituir como objeto de estudo as conexões e interações entre as diferentes formas de avaliação, e ponho em causa as chamadas políticas de responsabilização, sublinhando, em consequência disso, ser urgente pensar em formas alternativas de $a c$ countability.

\section{O CAMPO DA AVALIAÇÃO}

A avaliação educacional é um campo complexo que inclui, entre outras modalidades, a avaliação dos alunos, a avaliação dos profissionais (educadores e professores), a avaliação institucional das escolas, a avaliação dos sistemas ou subsistemas educativos, a avaliação de projetos e programas, e a própria

1 Trata-se da conferência de encerramento do VIII Congresso Internacional de Educação da UNISINOS/ III Congresso Internacional de Avaliação (Brasil, Gramado, 7 a 9 de outubro de 2013). Uma palavra de agradecimento a todas as pessoas que me proporcionaram esta oportunidade, salientando de forma especial a Prof ${ }^{a}$ Maria Isabel da Cunha, colega que muito estimo e considero, quer em termos pessoais, quer académicos. A organização do congresso, que de forma tão eficaz coordenou, permitiu criar um espaço particularmente propício à reflexão em torno da avaliação, do qual muito beneficiei em termos de interação humana e de enriquecimento teórico e metodológico. Também pude contar com o apoio do Centro de Investigação em Educação da Universidade do Minho (CIEd), e com a possibilidade de este trabalho ser parcialmente financiado por Fundos Nacionais através da FCT - Fundação para a Ciência e Tecnologia no âmbito do Projeto PEst-OE/CED/UI1661/2014. 
avaliação de políticas. A avaliação dos alunos é, portanto, apenas uma dimensão do vasto campo da avaliação educacional ${ }^{2}$.

Numa acepção lata, a avaliação dos alunos (também designada avaliação pedagógica ou avaliação das aprendizagens), sobretudo quando é desenvolvida no âmbito dos processos de escolarização formal, em torno dos quais se construíram os sistemas educativos, é uma prática que tem já uma história relativamente longa, que remonta, pelo menos, à época dos exames realizados na universidade medieval. Nessa mesma história, onde é possível reconhecer etapas e processos distintos em termos teórico-conceptuais e metodológicos (certamente nunca indiferentes às conjunturas sociais e políticas e à própria evolução do conhecimento) foi também inscrita, há pouco menos de um século, a proposta de criação e desenvolvimento de uma docimologia, enquanto ciência dos exames, de pendor experimental, quantitativista e psicologizante ${ }^{3}$.

A docimologia, apesar do relativo anacronismo da designação, não deixa de significar, do meu ponto de vista, um marco antecipatório daquilo que continua a ser hoje o debate em torno da possibilidade de a avaliação se constituir como disciplina científica autónoma (ou, mesmo, como transdisciplina) ${ }^{4}$. Mas, neste caso, trata-se de um debate muito mais amplo que já não se circunscreve aos exames, incluindo sobretudo a reflexão e pesquisa sobre muitas outras técnicas e metodologias de avaliação, mais avançadas e complexas, bem como sobre as dimensões concetuais, éticas e políticas que as contextualizam ou que delas decorrem.

Face a esta evolução, não é de estranhar que as políticas de avaliação neoconservadoras se situem nos antípodas das teorias da avaliação epistemologicamente mais avançadas. Com efeito, são justamente estas políticas que, em décadas mais recentes, têm recuperado as velhas fórmulas dos exames nacionais, ainda que atualizadas em aspetos técnico-metodológicos e concretizadas atra-

2 Considero a avaliação educacional como o conjunto de todas as formas de avaliação disponíveis no campo da educação. A este propósito, ver Afonso (2010a).

3 Como refere Gilbert de Landsheere (1976, p. 13), “A docimologia é uma ciência que tem como objecto o estudo sistemático dos exames, em particular do sistema de atribuição de notas e do comportamento dos examinadores e dos examinados". Todavia, o que parece estar hoje em maior evidência é a Teoria da Resposta ao Item (TRI) que alguns autores consideram como sendo a "versão contemporânea da psicometria" (ver, por exemplo, ZUKOWSKY-TAVARES, 2013, p. 62). Apesar dos avanços que reconhece, Freitas (2011, p. 13). sublinha que "Nem mesmo o advento de novas teorias de medição como a Teoria da Resposta ao Item significa a solução para as limitações clássicas dos testes" Para uma análise mais aprofundada sobre esta questão, ver Díaz-Barriga (2001).

4 Refletindo, na esteira de M. Scriven, a propósito da constituição da avaliação como disciplina ou, mesmo, como transdisciplina, Domingos Fernandes (2013, p. 18) escreve que têm persistido "dificuldades várias em determinar a sua área pura, o seu núcleo central de definições, de conceitos integradores, de pressupostos básicos ou de noções relativas aos seus próprios limites. Esta será uma das razões que tem vindo retardar a afirmação da avaliação como disciplina". 
vés de instrumentos estandardizados, supostamente mais válidos e fidedignos do que em épocas passadas. E são também essas políticas que continuam a remeter a avaliação, em geral, e os testes em larga escala, em particular, para um lugar instrumental ao serviço de certas visões e crenças ideológicas que valorizam apenas determinados conteúdos curriculares e, consequentemente, certas dimensões e processos de aprendizagem.

Nas últimas décadas, aliás, a avaliocracia (CORREIA, 2005; AFONSO, 2008) tornou-se dominante, invadindo não apenas os contextos tradicionais de interação pedagógica (como as salas de aula), mas também as organizações educativas (e não educativas), os sistemas de ensino e a própria administração pública. Esta obsessão avaliativa começou por contaminar os governos (nacionais, subnacionais e municipais), os quais, de forma crescente, passaram a agir em congruência com a ideologia avaliativa hegemónica.

Todavia, após o predomínio daquela que pode ser considerada a primeira fase de desenvolvimento do Estado-avaliador (AFONSO, 2013a), os usos da avaliação só são, hoje em dia, compreensíveis se forem analisadas as interseções (e mesmo contradições) entre as avaliações (relativamente autónomas) ao nível nacional e as avaliações e orientações a que muitos Estados aderem ou se vinculam em decorrência de serem membros de (ou terem relações de proximidade com) agências internacionais como a OCDE - que é, atualmente, um dos principais think tanks das políticas educativas a nível mundial, mesmo não sendo uma organização educativa. Com efeito, apesar dos défices que lhe podem ser atribuídos, programas como o Programme for International Student Assessment - PISA incorporam frequentemente novos aperfeiçoamentos metodológicos, e abrem-se a uma maior diversidade de dimensões, que parecem distingui-los de muitos dos testes comparativos em larga escala, de âmbito nacional.

Assim, apesar do refluxo neopositivista da primeira fase do Estado-avaliador, a história da avaliação continua também a fazer-se noutros sentidos. E não apenas em relação aos alunos, mas também, e cada vez mais, em relação a outros atores educativos, contextos, programas, projetos, níveis de ensino e políticas, através de uma investigação sistemática que avança na consistência da teoria, no aprofundamento da epistemologia, na diversificação das metodologias e na problematização das questões políticas e éticas que lhe dão fundamento ${ }^{5}$.

Também por isto, tendo esta complexidade sempre presente, seria desejável, entre muitos outros aspetos, não perder de vista (ou não naturalizar) a forma

5 A presença e interação destes fatores e dimensões traduz bem algumas das caraterísticas do campo da avaliação. Dito de outro modo, "Questões epistemológicas, éticas, ideológicas, políticas, culturais, técnicas e de outras naturezas imprimem complexidade a esse fenômeno" (DIAS SOBRINHO, 2004, p. 705). Ver também Dias Sobrinho (2008). 
reducionista como ocorre a receção de determinadas políticas, ou como se processa a interpretação, a reprodução ou a recontextualização das mesmas. Esta precaução é sobretudo importante num campo claramente saturado de avaliações (dos alunos, dos professores, das escolas, dos sistemas de ensino, dos projetos, dos programas e das próprias políticas educacionais). Nessa problematização incluem-se, naturalmente, os modelos, formas ou dispositivos de avaliação que, de forma isolada ou fragmentária, estão disponíveis e em concretização no campo escolar (tal como em diferentes contextos sociais e organizacionais). E é essa mesma problematização que pode contribuir para aprofundar criticamente (e constituir como problema e objeto de pesquisa) as interações, interseções, justaposições e consequências, dificilmente isentas de tensões ${ }^{6}$ e contradições, que se desenvolvem ou podem desenvolver, de modo intencional ou não intencional, entre os diferentes modelos, formas ou dispositivos de avaliação que vigoram num determinado sistema de ensino ou que são impostos por uma determinada política educativa ${ }^{7}$.

\section{A DISCUTÍVEL DOMINÂNCIA DA AVALIAÇÃO EXTERNA DOS ALUNOS}

Para ilustrar as centralidades e periferias das diferentes avaliações, pode convocar-se precisamente o caso da avaliação externa das aprendizagens dos alunos do ensino não superior. Indiferente às relações e interseções que sempre existem, implícita ou explicitamente, entre a avaliação profissional dos professores e/ou a avaliação institucional das escolas e, cada vez mais, entre estas e a avaliação das próprias políticas educacionais, a avaliação externa das aprendizagens dos alunos parece estar a ser assumida, de forma exagerada e muito discutível, como a única forma de avaliação estruturante e decisiva no

6 Como refere Mottiez Lopez, "Qui dit tensions dit pluralités ou, pour le moins, dualités. Tensions entre développement et contrôle, tensions entre implications locales et nationales, tensions entre individu, groupes d'intérêt et société, tensions entre micro, méso et macro [...] les tensions sont sources d'obstacles, de biais, de difficultés, de contradictions, d'incompréhensions, de ruptures, d'impossibilités. Quelques-uns ont pris le contre-pied, à savoir traiter la tension comme pouvant être productive, source de développement, source de nouvelles configurations, de réinventions, source de négociations et de significations construites" (MOTTIER LOPEZ, 2009, p. 17). Para uma perspetiva mais abrangente de toda a obra, ver Mottier Lopez; Crahay (2009).

7 A este propósito, num relatório da OCDE sobre a realidade portuguesa refere-se: "As in other OECD countries, the different components of evaluation and assessment have developed independently of each other over time and there is currently no policy document on the overall framework for evaluation and assessment in Portugal. At the national level, there are provisions for student assessment, school evaluation, teacher appraisal and system evaluation, but these are not explicitly integrated or aligned. The existing framework is not perceived as a coherent whole and it does not visibly connect all the different components" (SANTIAGO et al., 2012, p. 138). 
âmbito do ensino não superior, à qual todas as outras se subordinam ou (supostamente) devem subordinar. Com efeito, sobretudo nos níveis dos ensinos básico e secundário (ou fundamental e médio no caso brasileiro) a avaliação externa das aprendizagens dos alunos e os resultados mensuráveis que dela decorrem ditam, frequentemente, os parâmetros relativamente aos quais se referencia a avaliação dos professores, a avaliação das escolas e, até mesmo, de uma forma bastante mais arbitrária, a avaliação dos próprios sistemas educativos e das políticas educacionais.

Interessa, aliás, a muitos governos (que são também reforçados na sua ação pelas orientações ou pressões de organizações internacionais e supranacionais) que os resultados dos alunos, medidos através de provas externas e testes estandardizados (quer sob a forma censitária, quer através de amostragem representativa), sejam o foco principal para avaliar o funcionamento dos sistemas educativos e as políticas educacionais, uma vez que, desta forma, podem ser atingidos mais rapidamente vários objetivos: i) a governação pelos números e pelas evidências (GREK; OZGA, 2008; BORER; LAWN, 2013) ${ }^{8}$; ii) o controlo hiperburocrático (LIMA, 2011) sobre as escolas e o trabalho dos professores, seguindo a lógica da produtividade neotaylorista; iii) a indução de efeitos de comparação baseados em rankings escolares; iv) a imposição de lógicas de accountability baseadas em resultados mensuráveis, cujos destinatários preferenciais são o mercado e a comunidade (AFONSO, 2009); v) e ainda a descentração/desresponsabilização em relação a problemas diretamente imputáveis aos governos, mas que são transferidos para a responsabilidade dos atores, dos gestores escolares e das organizações educativas.

Não será, portanto, por acaso que se podem constatar apropriações abusivas ou apressadas dos resultados académicos dos alunos, na sequência, por exemplo, de avaliações em larga escala a nível nacional, e/ou de avaliações comparativas a nível internacional. É também sabido, por exemplo, que os resultados negativos dos alunos, obtidos na realização das provas do PISA da OCDE, têm servido para legitimar determinadas reorientações internas referentes às escolas e ao trabalho dos professores - e tudo isso no quadro de políticas educativas que raramente têm sofrido solução de continuidade apesar das diferenças ideológicas dos partidos que, num dado momento, sustentam a governação 9 .

8 Neste último trabalho, Valérie Borer e Martin Lawn (2013) designam esta forma de governação de "data/benchmarks-basead policies".

9 Mas, paradoxalmente, quando os resultados de alunos portugueses, em outras avaliações internacionais, parecem ser mais favoráveis o governo parece silenciá-los. Refiro-me, neste caso, ao atual governo de nova direita (coligação do PSD-Partido Social-Democrata, mais liberal, e do CDS-Partido Popular, mais conservador) que tomou posse em Portugal em 2011. Este silêncio, aliás, contrasta claramente com o teor mais otimista de um relatório do Conselho Nacional de Educação de Portugal onde se pode 


\section{INTERSECÇÕES, BÓNUS E PROFISSIONALISMO}

Em Portugal, já há alguns anos, vêm ocorrendo com regularidade no sistema de ensino provas externas de avaliação dos alunos, em paralelo com o desenvolvimento de modelos específicos de avaliação de professores e de avaliação externa das escolas. Apesar da continuidade e coexistência destes modelos e dispositivos de avaliação, as consequências das suas interações e intersecções, implícitas e explícitas, não têm sido discutidas, nem assumidas como objeto de estudo.

Noutros países, como o Brasil, essas interações e interfaces ganharam maior visibilidade social e interesse académico, sendo as suas consequências debatidas e traduzidas, em casos específicos e não sem alguma ambiguidade, pela expressão genérica de políticas de responsabilização ${ }^{10}$. Com efeito, na sequência de avaliações em larga escala, muitos governos têm importado ou recriado fórmulas, muito discutíveis do meu ponto de vista, visando sancionar negativamente, ou recompensar positivamente, escolas e professores pelos resultados académicos dos alunos. Concretamente, tem vindo a ampliar-se a introdução de bónus monetários, que são atribuídos de forma diferenciada aos professores ou às escolas, como consequência das performances discentes alcançadas.

Porém, uma reflexão crítica em relação às chamadas políticas de responsabilização não pode, todavia, deixar de ter em conta, entre muitos outros aspetos, que as formas de avaliação escolar adotadas nos vários países e sistemas educativos nunca podem ser indiferentes ao debate sobre conceções alternativas do trabalho dos professores, nem podem ficar à margem do aprofundamento político em torno dos objetivos mais amplos da educação.

Também por isso, interessa discutir as consequências das diferentes modalidades de avaliação quando se vive uma época em que há uma forte tendência para, na explicação dos resultados dos alunos ou na determinação dos rankings escolares, sobrevalorizar a ação didático-pedagógica dos professores.

ler que "Há hoje resultados muito expressivos em matéria de qualidade e equidade da educação e de desenvolvimento científico e tecnológico: a democratização do acesso a todos os níveis de ensino é uma realidade; há um crescente reconhecimento internacional da qualidade dos nossos diplomados; os resultados nos testes internacionais realizados pelos alunos portugueses são acentuadamente melhores, quer em termos de equidade (PISA, 2010), quer em termos de qualidade, designadamente em matemática, leitura e ciências no $1^{\circ}$ ciclo do Ensino Básico (MULLIS, c2012). É importante assinalar que nestes testes Portugal deixou os últimos lugares do ranking dos países avaliados para se colocar acima da média e em posição superior a alguns dos que tradicionalmente obtinham bons resultados (CNE, 2013, p. 9).

10 Do meu ponto de vista, a expressão pode ser equívoca porque tem sido usada em muitas situações como se dissesse respeito exclusivamente a consequências negativas ou a formas de culpabilização. Seria bem utilizada se a palavra responsabilização fosse entendida, consoante os casos, quer num sentido positivo (o de recompensa), quer num sentido negativo (o de punição) (SCHEDLER, 1999). 
Não é, portanto, por acaso que a responsabilização negativa (ou a culpabilização) dos professores constitui, em diferentes medidas de política educativa e nos discursos dominantes, uma das estratégias mais frequentes. Ela decorre, aliás, da indução da desconfiança social e política no seu trabalho e na sua formação (sobretudo no que diz respeito aos professores da escola pública), pretendendo assim justificar políticas de privatização e de liberalização, e a introdução de modelos não democráticos e coercitivos de accountability (AFONSO, 2009).

Isto explica, por exemplo, que a redução substancial da autonomia profissional dos professores, ou o impedimento de qualquer conquista nesse domínio, sejam concomitantes não apenas com o reforço do que é considerado o core curriculum, mas também com a imposição e sobrevalorização de formas de avaliação externas às escolas e, ainda, com a mobilização de novos panópticos de vigilância interna da sua ação educacional (nunca alheios, neste caso, a certos estilos de liderança ou a determinadas formas de administração e gestão escolar).

Do meu ponto de vista, que admito possa ser demasiado pessimista, passará ainda muito tempo até que se perceba que não é com políticas culpabilizantes e formas autoritárias de controlo, nem mesmo com bonificações conjunturalmente compensatórias, que se pode dignificar a profissão docente e conseguir que a escola pública passe a estar ao serviço, não de uma discriminação classista e meritocrática (encoberta por uma suposta neutralidade ou igualdade formal de oportunidades), mas sim ao serviço de uma "pluralidade de excelências" (COLLÈGE DE FRANCE; BOURDIEU, 1987), assumindo um compromisso com uma "qualidade negociada" (FREITAS, 2005) que seja também, tal como eu a entendo, uma qualidade simultaneamente científica, pedagógica e democrática.

Como antídoto à exacerbação da avaliação externa e suas consequências mais nefastas, uma avaliação institucional alternativa, enquanto responsabilidade assumida no âmbito da autonomia coletiva dos atores educativos, tem de ser congruente com a revalorização da avaliação formativa, ou de outras formas de avaliação comprometidas com a criação de condições reais de aprendizagem para todas/os, significando, assim, a reposição da confiança nos professores e o reconhecimento da importância de processos partilhados e dialógicos que envolvam os docentes enquanto profissionais, os estudantes, a comunidade e o próprio Estado.

Relaciona-se muito bem com esta perspetiva o que Mara Sordi e Luiz Carlos de Freitas designam de "responsabilização participativa". Para estes autores,

A responsabilização participativa inscreve-se como forma de contraregulação $[. .$.$] e envolve esforços coordenados dos múltiplos atores$ 
interessados na defesa de uma qualidade educacional que se confronte com a lógica das políticas imediatistas e restritas a interesses específicos de setores econômicos. Implica exercitar o coletivo da escola em processos de apropriação dos problemas do cotidiano e refletir sobre o futuro, principal função dos processos avaliativos (SORDI; FREITAS, 2013, p. 91).

Do meu ponto de vista, a introdução de bonificações (que é uma forma parcelar de uma conceção conservadora de accountability) ilude e protela o enfrentamento das questões anteriores e de outras questões fundamentais. Diversos estudos revelam que os seus efeitos ou não são os esperados, ou aparecem referidos como não sendo conclusivos relativamente aos objetivos pretendidos, ou são vistos como tendo consequências contraproducentes. Não critico, porém, os professores ou as escolas que, perante salários muito baixos e escassez de recursos públicos disponíveis, aderem a estas bonificações. O que digo é que elas são um paliativo que não resolve (nem sequer ameniza) os problemas estruturais. Neste sentido, partilho do ponto de vista de todos aqueles que referem ser muito melhor, mais urgente e mais justo, aumentar significativamente os salários dos professores, adotar modelos de avaliação profissional amplamente discutidos e democraticamente consensualizados, e dignificar de vez o seu estatuto socioprofissional.

\section{A AVALIAÇÃO NO CAPITALISMO E A SUA CRESCENTE INTERNACIONALIZAÇÃO}

Outro facto que quero aqui pontuar diz respeito à internacionalização crescente dos processos avaliativos, que também poderíamos designar de globalização da avaliação. Com efeito, como muito bem salienta Isabel Cunha (2011, p. 565),

\footnotetext{
Mesmo considerando a avaliação como uma prática secular na relação dos homens com o mundo produtivo - em que a escola se constitui num exemplo peculiar - é preciso registrar como essa dimensão do trabalho humano potencializou sua importância, na medida em que as estruturas capitalistas globalizadas se instituíram de forma efetiva.
}

Todavia, ao longo da sua história, a avaliação em educação foi, antes de mais, avaliação circunscrita ao contexto nacional e às lógicas do Estado-nação. Não é por acaso que os exames tradicionais estiveram e ainda continuam a estar (embora, atualmente, sob a forma de provas padronizadas ou estandardizadas) 
fortemente associados ao Estado e à racionalidade legal-burocrática que acompanhou o desenvolvimento dos sistemas administrativos (em ambos os casos, quase sempre ao serviço da expansão do próprio capitalismo).

Com efeito, esta relação ficou muito nítida ao longo do século XIX quando se assistiu à multiplicação dos exames modernos, pondo em evidência o contínuo controlo dos processos de certificação escolar por parte do Estado. Como Karl Marx observou, o exame é o "laço objetivo entre o saber da sociedade civil e o saber do Estado, é apenas o batismo burocrático do saber, o reconhecimento oficial da transubstanciação do saber profano em saber sagrado" (MARX, 2010, p. 70). Também, a este propósito, o sociólogo Jean-Claude Passeron refere que a permanência dos exames nos sistemas de ensino pode ser entendida como uma "sobrevivência característica de uma época histórica (a do nascimento do Estado burguês e do capitalismo)" em que as organizações burocráticas, públicas e privadas, desejavam recrutar indivíduos já "hierarquizados e catalogados uma vez por todas" (PASSERON, 1970, p. 7). Outros autores escreveram sobre os exames tradicionais ${ }^{11}$, em muitos casos chamando a atenção para as relações que (direta ou indiretamente) mantêm com as lógicas do Estado-nação e os interesses das classes dominantes - as quais, valorizando esses instrumentos de avaliação, acriticamente considerados neutros quando aplicados tendo como pressuposto uma mera igualdade formal de oportunidades, conseguem continuar a garantir uma seleção supostamente meritocrática através da escola, mantendo, pelo menos em parte, os privilégios anteriormente conferidos pelo nascimento ou pela fortuna. Foi, possivelmente, para salientar este processo que o historiador da educação, Rogério Fernandes, escreveu (ainda em pleno período revolucionário português, que se seguiu à mudança para o regime democrático em Abril de 1974) que o apogeu dos exames coincide com o período de ascensão e consolidação da burguesia, continuando a ser "uma das peças" do sistema económico capitalista (FERNANDES, 1976, p. 11-12).

No que diz respeito a Portugal, os exames nacionais foram uma pedra angular do sistema educativo durante quase meio século de regime autoritário e não terá sido por acaso que os mesmos foram postos em questão e abolidos após a Revolução dos Cravos de abril de 1974. Porém, passadas duas décadas, e completada a normalização que repôs o capitalismo e a democracia representativa na sociedade portuguesa, os governos mais neoconservadores e neoliberais (mas não apenas esses) foram gradualmente reintroduzindo os exames nacionais, agora já não na sua forma tradicional, mas com a nova configuração de provas de avaliação padronizadas ou de testes estandardizados.

11 Ver a este propósito, por exemplo, a excelente coletânea organizada por Díaz-Barriga (1993). 
A nível internacional, na viragem dos anos 1980, inicialmente pela mão de governos da chamada nova direita (que, por essa altura, chegaram ao poder em países centrais como os EUA e a Inglaterra), os exames nacionais regressaram em força, mas com uma particularidade inédita: pelo lado dos neoconservadores, foram usados como instrumentos de controlo por parte do Estado, sobretudo em relação ao currículo e ao trabalho dos professores; pelo lado dos neoliberais, foram usados como condição necessária para induzir efeitos de mercado (ou seja, competição, comparação, liberdade de escolha, cheques-ensino...) nos sistemas educativos, nomeadamente através da publicitação dos resultados desses mesmos exames e da transformação dos pais e famílias em novos consumidores de bens educativos com vista a serem transformados em bens posicionais. Este período híbrido não foi esgotado, como lembra M. W. Apple (2007), ${ }^{12}$ embora coincida, em grande medida, com o que tenho chamado de primeira fase do Estado-avaliador (AFONSO, 2013a).

Esta primeira fase do Estado-avaliador corresponde a um período em que a autonomia relativa do Estado nacional na definição das políticas públicas ainda é significativa. Neste contexto político-ideológico, a nova vaga de exames nacionais e testes estandardizados visou, como já anteriormente referi, um maior controlo da ação dos professores e das escolas, no sentido de melhorar os resultados escolares que, supostamente, seriam mais baixos do que o expectável, por razões relacionadas com a dominância de metodologias não diretivas progressistas ou de modelos construtivistas que, reconhecendo e valorizando o protagonismo dos alunos, descentravam a figura do professor e atenuavam a sua autoridade científico-pedagógica. Como consequência, os ataques do conservadorismo neoliberal à escola pública passaram, entre outros aspetos, pela dramatização da diminuição da eficácia do ensino e da aprendizagem, medida, neste caso, por avaliações comparativas, sobretudo em matérias curriculares consideradas centrais (core curriculum) para a competitividade económica e para a subida de lugares nos rankings nacionais e internacionais.

Foi também neste período, correspondente à primeira fase do Estado-avaliador, que os testes em larga escala se diversificaram e disseminaram, sendo paradigmático, por exemplo, o que ocorreu uma década mais tarde no Brasil com a implementação gradual do SAEB, da Prova Brasil, do ENEM, do IDEB e de todas as variantes que assumem, em diferentes avaliações, diferentes funções e objetivos, ou que traduzem especificidades dos estados que integram a União.

12 Como refere M. W. Apple (2007, p. 4), "The odd combination of marketization on the hand and centralization of control on the other is not only occurring in education; nor is it only going on in the United States. This is a world-wide phenomenon". 
Naturalmente que a preocupação com o lugar de cada país num ranking de desempenho escolar dos seus alunos, em confronto com alunos de outros países (e a participação, esporádica e não sistemática, em avaliações comparativas internacionais) foram também, do meu ponto de vista, indutoras da expansão dos exames e testes estandardizados nacionais, embora estes fatores estivessem nessa primeira fase (ainda e sobretudo) determinados por questões internas de índole político-ideológica.

No período subsequente - que designo de segunda fase do Estado-avaliador - o que começa a marcar a agenda a nível nacional são as crescentes repercussões da globalização (ou das globalizações económica, política e cultural), cuja expressão mais forte é precisamente a internacionalização acelerada da economia capitalista, induzida, entre muitos outros fatores, pela expansão das tecnologias da informação e comunicação, pelas mudanças no trabalho e nos sistemas produtivos e pelo fim da bipolarização das principais potências mundiais, traduzindo, por um lado, o fracasso do chamado socialismo real e, por outro, o fortalecimento da hegemonia dos EUA. Tudo isto contribuiu para esbater as fronteiras nacionais e a autonomia relativa dos Estados, sobretudo os que se situam na periferia e semiperiferia do sistema mundial. Paralelamente, assumem crescente protagonismo as instâncias e agências internacionais e transnacionais (União Europeia, Mercosul, OCDE, Banco Mundial...).

Embora as primeiras avaliações internacionais tenham começado há mais ou menos $50 \operatorname{anos}^{13}$, é na segunda fase do Estado-avaliador que elas se consolidam, sendo exemplo disso o já atrás referido PISA da OCDE ao qual têm aderido cada vez mais países membros e não membros desta organização económica.

Mas talvez seja na avaliação do ensino superior (e nos sistemas internos de garantia da qualidade) onde hoje se sente mais fortemente (e explicitamente) o papel de agências internacionais, como a European Association for Quality Assurance in Higher Education (ENQA, 2005). Em relação a Portugal, o que acabei de afirmar pode ser facilmente confirmado pelo papel central que tem hoje a Agência de Avaliação e Acreditação do Ensino Superior (AFONSO, 2013b).

Entre muitas outras, constitui também uma característica importante da segunda fase do Estado-avaliador a "relativa indiferença da avaliação às conceções político-ideológicas”, por oposição a políticas de avaliação que, na primeira

13 Com efeito, talvez a mais antiga organização neste campo - "a International Association for the Evaluation of Educational Achievement (IEA) - tornou-se uma pessoa jurídica em 1967, mas as suas origens remontam a 1958, quando um grupo de estudiosos, psicopedagogos, sociólogos e psicometristas se reuniram no Instituto de Educação da UNESCO, em Hamburgo, na Alemanha, para discutir os problemas da escola e da avaliação dos alunos". Disponível em: $<$ http://www.iea.nl/brief_history.html>. Acesso em: 3 mar. 2014 
fase, foram claramente conotadas com a ideologia neoliberal e neoconservadora (AFONSO, 2007, p. 17; AFONSO, 1999).

Finalmente, não podendo fazer uma projeção segura da evolução daquilo que, muito sucintamente, acabei de afirmar, parece-me que já há alguns indícios que permitem sugerir a hipótese de uma terceira fase do Estado-avaliador onde, por exemplo, agências como a Organização Mundial do Comércio (OMC) continuarão a fazer tudo para induzir mais processos de liberalização e de mercadorização da educação, nomeadamente aqueles que já estão em curso através da expansão internacional dos sistemas de franchising, da modularização e estandardização curricular e da ampliação dos sistemas e agências de avaliação, eventualmente retirados num futuro próximo do controlo autónomo dos Estado-nacionais, tal como acontece hoje com as chamadas agências de rating. Observo ainda, de passagem, que não estou defendendo nenhuma perspetiva evolucionista no que diz respeito às fases do Estado-avaliador aqui sugeridas. Do meu ponto de vista, e considerando a análise de diferentes realidades nacionais e educacionais, todas as combinatórias dessas três fases são possíveis, estando as mesmas já a ocorrer, ou podendo vir a ocorrer, em simultâneo ou não, e em intensidades variadas consoantes os contextos nacionais e internacionais (AFONSO, 2013a).

\section{MEDIR AS CONSEQUÊNCIAS DA AVALIAÇÃO}

Há uma série de consequências da avaliação que vão sendo impostas e adotadas, por uma grande parte dos países capitalistas, em nome da democraticidade e da transparência e sob a designação de prestação de contas, responsabilização ou, mais genericamente, de accountability. A este propósito, quero sublinhar, desde já, que estes termos, apesar de andarem frequentemente juntos, não têm o mesmo significado, nem semântico, nem político, nem educacional.

$\mathrm{Na}$ ciência política tradicional, é quase um lugar-comum referir que o exercício do controlo social é uma das funções originárias do Estado enquanto aparelho político-administrativo que exerce várias funções, entre as quais as que decorrem do facto de deter o monopólio do uso da violência legítima (na aceção de Max Weber). Quando o controlo social é exercido por um Estado autoritário e não democrático, ou mesmo quando se trata de uma sociedade democrática, os cidadãos podem ser fisicamente coagidos a ser submissos ao Estado, em paralelo ou não com o uso de mecanismos de violência simbólica (tal como Pierre Bourdieu a caracterizou).

Mas o controlo social, numa aceção democrática e participativa pode e deve ser compreendido, pensado e exercido de um outra forma (penso ser esta, 
aliás, a aceção que no Brasil é dada frequentemente à ideia de controlo social). Trata-se de um controlo que parte dos cidadãos e é exercido pelos cidadãos ou organizações da sociedade civil, os quais, enquanto tal, sem esquecer os seus deveres e no uso dos seus direitos democráticos, têm legitimidade para participar e ajudar a construir soluções em processos de concertação social (como acontece, por exemplo, com o Orçamento Participativo). Nestes processos, os cidadãos e cidadãs evidenciam também vontade de acompanhar e avaliar criticamente a ação do Estado e dos poderes públicos, devendo os seus agentes e instituições ser o mais transparentes possível, prestando contas e, quando necessário, sendo responsabilizados pela sua ação (ou omissão) em relação ao bem comum. Isto não é senão uma forma de accountability vertical, tal como a definiu O’Donnell (1998).

Se recuarmos um pouco no tempo, veremos que a questão da accountability tem já uma longa história. Não é difícil encontrar exemplos de práticas a ela referenciáveis já no século XIX ou em outros contextos e conjunturas. Nos sistemas de ensino, centralmente administrados e fortemente hierarquizados, podemos dizer que sempre existiram formas parcelares de accountability racional-legal, sendo comum a responsabilização dos subordinados por parte dos superiores, em relação ao cumprimento das normas legais, programas de ação ou quaisquer outras orientações e regras formais. Na educação pública, em regimes autoritários, mas não só, isso aconteceu historicamente, sobretudo ao nível da escolaridade básica e obrigatória, uma vez que ela se constituiu como lugar por excelência da construção de uma cidadania restrita às lógicas do Estado-nação. Não por acaso, em Portugal, os professores do antigo ensino primário (que era na altura do Estado Novo a escolaridade básica obrigatória) foram sempre mais controlados e vigiados do que os seus colegas de outros níveis de ensino, quer em termos de ação educativa, quer em termos político-ideológicos.

Em décadas mais recentes, como atrás sugeri, a assunção mais explícita da função avaliativa por parte do Estado (que tem sido interpretada como a emergência do chamado Estado-avaliador) passou a implicar a articulação relativamente sincrónica (e em muitos casos contraditória) de mecanismos de accountability que deixaram de ser meramente burocráticos ou internos ao sistema educativo. Mais especificamente, a manutenção do controlo hierárquico do Estado (nomeadamente sobre os currículos escolares e a ação dos professores) passou a coexistir com a publicitação dos resultados académicos, indutores de lógicas de mercado (e, algumas vezes, paradoxalmente, de lógicas anti-Estado). Assim, num contexto politicamente ambivalente e fortemente marcado pelas 
ideologias neoconservadora e neoliberal, o controlo sobre os resultados escolares não tem sido subordinado, nem tem sido restringido, a uma mera lógica burocrática interna aos sistemas educativos — é isto, aliás, que torna a atuação do Estado claramente distinta em relação a estratégias adotadas em outras épocas e em outros contextos históricos (AFONSO, 1998).

Embora haja diferentes modelos de accountability que integram, em combinatórias várias, os pilares da avaliação, da prestação de contas e da responsabilização (AFONSO, 2010b; AFONSO, 2012), o modelo defendido pelas ideologias neoconservadoras e neoliberais (atualmente hegemónicas em muitos países) é essencialmente um modelo misto no qual os diferentes pilares se dividem entre o Estado e a sociedade civil (e, neste último caso, com um apelo mais direcionado ao mercado). Assim, a prestação de contas à sociedade e ao mercado é feita através da divulgação pública de rankings que comparam resultados escolares dos alunos e, através deles, fazem a seriação das respetivas escolas. Este modelo contém ainda dimensões típicas de mercado porque pressupõe a oferta e a procura, a liberdade de escolha, a competição entre o público e o privado e a expetativa de que os indivíduos devem agir não como cidadãos mas como consumidores da educação. Porém, a administração do pilar da avaliação e as sanções negativas ou as recompensas/bonificações (referentes ao pilar da responsabilização) são controladas e administradas pelo Estado, pelo menos no que diz respeito às escolas públicas.

Nos casos mais radicais, como acontece nos EUA, o desempenho das escolas e dos professores pode levar ao fechamento dos próprios estabelecimentos de ensino. Nesta situação, a responsabilização é coercitiva e não democrática, transformando-se em culpabilização, e constituindo, assim, uma verdadeira ameaça que pesa sobre os estudantes e os profissionais da educação.

Porém, a problemática da accountability é muito mais complexa, podendo (e devendo) assumir uma configuração progressista que a relocalize nos antípodas do senso comum e longe das versões mais neoconservadores e neoliberais. Muito embora a minha posição possa parecer utópica, é isso que venho defendendo, na esteira, aliás, de muitos autores com os quais me identifico nesta questão. Mas reconheço a controvérsia (tão salutar e tão pouco partilhada e exercitada no nosso meio académico).

A este propósito, refiro aqui a reação crítica de um autor, Nigel Brooke, que há bastante tempo vem escrevendo sobre a problemática da accountability no Brasil:

Tanto a proposta de Accountability Inteligente como a de Accountability Democraticamente Avançada, defendidas por Afonso, reque- 
reriam, para a escola, uma reengenharia social e institucional de tal tamanho que a obra ficaria eternamente incompleta. Haveria necessidade de instrumentos avaliativos diversos com abordagens mais inclusivas e deliberativas, abrangendo grupos de discussão e fóruns públicos, tempos mais longos e mudanças nos valores de todos os grupos sociais envolvidos para atenuar as desigualdades de poder e outras assimetrias. Por mais que se queira fugir das soluções de curto prazo, sugerir como alternativa à accountability baseada na avaliação quantitativa, um mundo novo, hipotético, sem exemplos conhecidos, e cuja viabilidade prática parece duvidosa, mais uma vez, retira a discussão do campo das políticas públicas (BROOKE, 2013, p. 338).

Reconheço, sem dúvida, a pertinência de alguns argumentos, mas quero insistir nessa utopia (no sentido clássico que os gregos lhe davam). Na verdade, apesar de existirem conotações negativas que tantas vezes carrega - fruto, em grande medida, do seu atual enclausuramento reacionário ${ }^{14}$-, a accountability pode ser definida e praticada de muitas maneiras diferentes e pode adquirir uma expressiva densidade teórica e conceptual (ver, por exemplo, MURPHY, 2009; SUSPITSYNA, 2010).

Em primeiro lugar, essa densidade decorre de um background teórico-conceptual amplo e de um campo especializado onde estão disponíveis várias metodologias possíveis de avaliação; em segundo lugar, a prestação de contas implica justificações e fundamentações que são distintas consoante se trate de assumir formas dialógicas, críticas e argumentativas, ou, pelo contrário, formas burocráticas, hierárquicas e não participativas; em terceiro lugar, como já atrás referi, a responsabilização não tem de ser necessariamente negativa.

Isto exige que a responsabilização não seja confundida nem com responsabilidade coletiva nem com culpabilização individual (ARENDT, 2004), podendo e devendo ser pensada, sobretudo, como lugar em que se medem as consequências decorrentes de uma determinada ação política, educacional ou social. Dito de outro modo, na minha perspetiva, um modelo de accountability deve ser um conjunto de relações articulado e sustentável, não apenas na sua dimensão argumentativa e dialógica, mas também nas suas dimensões avaliativas, políticas, éticas e metodológicas, ainda que nunca isento de tensões ou contradições, nomeadamente entre

14 Não posso, neste momento, desenvolver a justificação desta afirmação (que poderá não ser tão óbvia como parece), mas quero remeter o leitor para a leitura de um dos livros mais sugestivos de Albert O. Hirschman - The rethoric of reaction - onde o autor começa por discutir as noções de reação e reacionário. O livro foi traduzido para português com o título: O Pensamento Conservador-perversidade, futilidade e risco. Lisboa: Difel, 1997. 
os seus pilares fundamentais (avaliação, prestação de contas e responsabilização). Por isso, no campo da educação, uma visão crítica e avançada de accountability deve, entre outros aspetos, pôr em confronto uma visão hegemónica e uma visão contra-hegemónica, assente, neste último caso, numa conceção de democracia mais avançada e numa partilha de poder (ver a este propósito, por exemplo, MATHISON; ROSS, 2002).

Não pode, portanto, fugir-se à medição das consequências pessoais, coletivas, educacionais, éticas e políticas dos modelos ou sistemas de avaliação e de prestação de contas, incluindo nesse processo de reflexividade crítica, inevitavelmente, as próprias formas de responsabilização.

Certamente que os modelos de accountability em educação podem servir a vários interesses, dado que a própria educação também não é, nem pode ser, ideologicamente neutra, nem culturalmente assética. Por isso, não há nenhuma razão para não pensarmos ou não escrevermos no sentido de contribuir para resgatar o atual enclausuramento unidimensional da accountability, chamando a atenção para a necessidade de pensar outras alternativas que sejam mais densas e sustentáveis do ponto de vista teórico-conceptual e/ou que demonstrem ter outra pertinência política e educacional. Mas sabemos também que é preciso o exercício da coragem cívica para pôr em prática, na realidade das escolas e dos sistemas educativos, essas mesmas alternativas. E este é, certamente, um dos desafios (culturais e políticos) que todos temos pela frente.

\section{REFERÊNCIAS}

AFONSO, Almerindo J. Políticas educativas e avaliação educacional. Braga: Universidade do Minho, 1998.

AFONSO, Almerindo J. Estado, mercado, comunidade e avaliação: esboço para uma rearticulação crítica. Educação \& Sociedade, Campinas, v. 20, n. 69, p. 139-164, 1999.

AFONSO, Almerindo J. Estado, políticas educacionais e obsessão avaliativa. Revista Contrapontos, Itajaí, v. 7, n. 1, p. 11-22, 2007.

AFONSO, Almerindo J. Para uma crítica da avaliocracia. OPS! Revista de Opinião Socialista, Lisboa, n. 2, p. 14-16, 2008. 
AFONSO, Almerindo J. Nem tudo o que conta é mensurável ou comparável. Crítica à accountability baseada em testes estandardizados e rankings escolares. Revista Lusófona de Educação, Lisboa, v. 13, n.1, p. 13-29, 2009.

AFONSO, Almerindo J. Avaliação educacional. In: OLIVEIRA, Dalila A.; DUARTE, Adriana; VIEIRA, Lívia (Orgs.). Dicionário sobre trabalho, profissão e condição docente. Brasília: SEB/ MEC, 2010a. Disponível em: $<$ http://www.gestrado.org/?pg=dicionario-verbetes\&id=363>. Acesso em: 3 mar. 2014.

AFONSO, Almerindo J. Um olhar sociológico em torno da accountability em educação. In: ESTEBAN, Maria Teresa; AFONSO, Almerindo J. (Orgs.). Olhares e interfaces. Reflexões críticas sobre a avaliação. São Paulo: Cortez, 2010b. p. 147-170.

AFONSO, Almerindo J. Para uma concetualização alternativa de accountability na educação. Educação \& Sociedade, Campinas, v. 33, n. 119, p. 471-484, 2012.

AFONSO, Almerindo J. Mudanças no Estado-avaliador: comparativismo internacional e teoria da modernização revisitada. Revista Brasileira de Educação, Brasilia, v.18, n. 53, p. 267-280, 2013 a.

AFONSO, Almerindo J. Ensaio sobre a accountability no ensino superior em Portugal (1976-2013). Discursos, formas parcelares e modelo atual. In: SOUSA, José Vieira de (Org.). Educação superior: cenários, impasses e propostas. Campinas: Autores Associados, 2013 b.

APPLE, Michael W. Education, markets, and the audit culture.

International Journal of Educational Policies, Ankara- Turkey, v. 1, n. 1, p. 4-19, 2007.

ARENDT, Hannah. Responsabilidade e julgamento. São Paulo: Companhia das Letras, 2004.

BORER, Valérie L.; LAWN, Martin. Governing education systems by shaping data: from the past to the present, from national to international perspectives. European Educational Research Journal, Oxford, v. 12, n. 1, p. $48-52,2013$. 
BROOKE, Nigel. Controvérsias sobre políticas de alto impacto. Cadernos de Pesquisa, São Paulo, v. 43, n. 148, p. 336-347, 2013.

CNE - CONSELHO NACIONAL DE EDUCAÇÃO. Estado da Educação 2012. Autonomia e descentralização. Lisboa: CNE, 2013.

COLLĖGE DE FRANCE/ BOURDIEU, Pierre. Propostas para o ensino do futuro. Revista Cadernos de Ciências Sociais, Porto, n. 5, p. 101-120, 1987.

CORREIA, José Alberto. Contributos para a construção de 'narrativas educativas' de esquerda. Perspectiva, Florianópolis, v. 23, n. 2, p. 407-426, 2005.

CUNHA, Maria Isabel da. Aprendizagem ao longo da vida e avaliação do desempenho profissional. Avaliação, Campinas; Sorocaba, SP, v. 16, n. 3, p. 559-572, 2011.

DE LANDSHEERE, Gilbert. Avaliação contínua e exames. Noções de docimologia. Coimbra: Almedina, 1976.

DIAS SOBRINHO, José. Avaliação Educativa: produção de sentidos com valor de formação. Avaliação, Campinas; Sorocaba, SP, v. 13, n. 1, p. $193-$ 207, 2008.

DIAS SOBRINHO, José. Avaliação ética e política em função da educação como direito público ou como mercadoria? Educação \& Sociedade, v. 25, n. 88, p. $703-724,2004$.

DIAZ-BARRIGA, Ángel (Org.). El Examen. Textos para su história y debate. México, D.F., 1993.

DÍAZ-BARRIGA, Ángel. Teoría del test, nuevos desarrollos en las pruebas a gran escala y la prueba PISA 2006. In: DÍAZ-BARRIGA, Ángel (Org.). La Prueba PISA 2006. Una análisis de su visión sobre la ciência. México: UNAM, 2001. p- 53-79.

ENQA - EUROPEAN ASSOCIATION FOR QUALITY ASSURANCE IN HIGHER EDUCATION. Standards and Guidelines for Quality Assurance in the European Higher Education Area. Helsinki: ENQA, 2005. 
FERNANDES, Domingos. A avaliação em educação: uma discussão de algumas questões críticas e desafios a enfrentar nos próximos anos. Ensaio, Rio de Janeiro, v. 21, n. 78, p. 11-34, 2013.

FERNANDES, Rogério. Prefácio à edição portuguesa. In: BONBOIR, Anna. Como avaliar os alunos. Lisboa: Seara Nova, 1976. p. 11-14.

FREITAS, Luiz Carlos. Qualidade negociada: avaliação e contra-regulação na escola pública. Educação \& Sociedade, Campinas, v. 26, n. 92, p. 911$933,2005$.

FREITAS, Luiz Carlos. Responsabilização, meritocracia e privatização: conseguiremos escapar ao neotecnicismo? SEMINÁRIO DE EDUCAÇÃO BRASILEIRA, 3. Simpósio PNE - Diretrizes para Avaliação e Regulação da Educação Nacional. Campinas: CEDES, 2011.

GREK, Sotiria; OZGA, Jenny. Governing by numbers? Shaping education through data. CES Briefing, Scotland, n. 44, 2008. Disponível em: <http:// www.ces.ed.ac.uk/PDF\%20Files/Brief044.pdf>. Acesso em: 3 mar. 2014.

LIMA, Licínio C. Avaliação, competitividade e hiperburocracia. In: ALVES, Palmira; DE-KETELE, Jean-Marie (Orgs.). Do currículo à avaliação, da avaliação ao currículo. Porto: Porto Editora, 2011. p. 71-82.

MARX, Karl. Crítica da filosofia do Direito de Hegel. 2. ed. São Paulo: Boitempo, 2010.

MATHISON, Sandra; ROSS, E. Wayne. The hegemony of accountability in schools and universities. Workplace: A Journal for Academic Labor, Cambridge, v. 5, n. 1, 2002. Disponível em: <http://louisville.edu/journal/ workplace/issue5p1/mathison.html>. Acesso em: 3 mar. 2014.

MULLIS, Ina V.S. et al. TIMSS 2011 International Results in Mathematics. Chestnut Hill: TIMSS \& PIRLS, c2012. Disponível em: $<$ http://timssandpirls.bc.edu/timss2011/downloads/T11_IR_Mathematics FullBook.pdf>. Acesso em: 3 mar. 2014.

MOTTIER LOPEZ, Lucie. L' évaluation en education: des tensions aux controverses. In: MOTTIER LOPEZ, Lucie; CRAHAY, Marcel (Orgs.). Évaluations en Tension. Bruxelles: De Boeck, 2009, p. 7-25. 
MURPHY, Mark. Bureaucracy and its limits: accountability and rationality in higher education. British Journal of Sociology of Education, London, v. 30, n. 6, p. 683-695, 2009.

O'DONNELL, Guilhermo. Accountability horizontal e novas poliarquias. Lua Nova, São Paulo, n. 44, p. 27-54, 1998.

PASSERON, Jean-Claude. Sociologie des examens. Éducation et Gestion, Marseille, n. 20, p. 6-16, 1970.

PISA - PROGRAMME FOR INTERNATIONAL STUDENT

ASSESSMENT. PISA 2009: Competências dos Alunos Portugueses. Lisboa, OCDE, 2010. Disponível em: <http://www.gave.min-edu.pt/np3content/?ne wsId=346\&fileName=Apres_Gulb_Final.pdf $>$. Acesso em: 3 mar. 2014

SANTIAGO, Paulo et al. OECD Reviews of Evaluation and Assessment in Education. Portugal 2012. Lisboa: OECD Pub., 2012.

SCHEDLER, Andreas. Conceptualizing accountability. In: SCHEDLER, Andreas; DIAMOND, Larry; PLATTNER, Marc (Eds.). The sef-restraining state. Power and accountability in new democracies. London: Lynne Reinner Pub, 1999.

SORDI, Mara. R. \& FREITAS, Luiz C. Responsabilização participativa. Revista Retratos da Escola, Brasília, v.7, n. 12, p. 87-99, 2013.

SUSPITSYNA, Tatiana. Accountability in American education as rhetoric and a technology of governmentality. Journal of education policy, London, v. 25 , n. 5 , p. $567-586,2010$.

ZUKOWSKY-TAVARES, Cristina. Teoria da Resposta ao Item: uma análise crítica dos pressupostos epistemológicos. Estudos em Avaliação Educacional, São Paulo, v. 24, n. 54, p. 56-76, 2013. 
